\title{
Interaction of Tomato Spotted Wilt Tospovirus (TSWV) Glycoproteins with a Thrips Midgut Protein, a Potential Cellular Receptor for TSWV
}

\author{
M. D. Bandla, L. R. Campbell, D. E. Ullman, and J. L. Sherwood
}

First and fourth authors: Department of Plant Pathology, Oklahoma State University, Stillwater 74078; and second and third authors: Department of Entomology, University of California, Davis 95616.

Accepted for publication 14 November 1997.

\begin{abstract}
Bandla, M. D., Campbell, L. R., Ullman, D. E., and Sherwood, J. L. 1998. Interaction of tomato spotted wilt tospovirus (TSWV) glycoproteins with a thrips midgut protein, a potential cellular receptor for TSWV. Phytopathology 88:98-104.

Interactions between viral and cellular membrane fusion proteins mediate virus penetration of cells for many arthropod-borne viruses. Electron microscope observations and circumstantial evidence indicate insect acquisition of tomato spotted wilt virus (TSWV) (genus Tospovirus, family Bunyaviridae) is receptor mediated, and TSWV membrane glycoproteins (GP1 and GP2) serve as virus attachment proteins. The tospoviruses are plant-infecting members of the family Bunyaviridae and are

mine whether a corresponding cellular receptor may be present in $\mathrm{F}$. occidentalis. A single band in the $50-\mathrm{kDa}$ region was detected with murine monoclonal antibodies (MAbs) to the TSWV-GPs when isolated TSWV or TSWV-GPs were used to overlay separated thrips proteins. This band was not detected when blots were probed with antibody to the nonstructural protein encoded by the small RNA of TSWV or the TSWV nucleocapsid protein, nor were proteins from nonvector insects labeled. Anti-idiotype antibodies prepared to murine MAbs against GP1 or GP2 specifically labeled a single band at $50 \mathrm{kDa}$ in Western blots and the plasmalemma of larval thrips midguts. These results support the putative role of the TSWV GPs as viral attachment proteins and identified potential cellular receptor(s) in thrips.
\end{abstract} transmitted by several thrips species, including Frankliniella occidentalis. Gel overlay assays and immunolabeling were used to investigate the putative role of TSWV GPs as viral attachment proteins and deter-
Additional keywords: insect vector, ligand, plant virus, virus acquisition, western flower thrips.
Transmission of arthropod-borne viruses of plants and animals depends on intricate relationships that exist between the virus, the vector arthropod and the plant or animal host. It has long been recognized that a significant component of vector competence involves dissemination of ingested virus across midgut barriers (12). A wide range of studies have demonstrated that viral and cellular membrane fusion proteins interact to mediate virus penetration of cells (reviewed in [36]). Many arthropod-borne viruses have membrane glycoproteins (GPs) that serve as viral attachment proteins that interact with cellular receptors to mediate entry to the insect midgut and other organs (i.e., La Crosse virus [LACV]), a bunyavirus, and western equine encephalomyelitis virus (WEEV), an alphavirus $(14,19,20,25)$.

All the viruses in the family Bunyaviridae are membrane bound and have two membrane GPs (GP1 and GP2) (25). Tomato spotted wilt virus (TSWV) is the type member of the genus Tospovirus, the only genus in the family Bunyaviridae with plant-infecting members. TSWV is spread between plant hosts by several species of thrips vectors, the most ubiquitous of which is Frankliniella occidentalis (Thysanoptera: Thripidae). We previously demonstrated that TSWV is acquired by larval $F$. occidentalis via entry to the midgut epithelial cells $(29,31)$, whereas adults were refractory due to a midgut barrier (28). These findings were consistent with biological data indicating adults capable of transmission only result if the virus is acquired during the larval stages (23). Although a $F$. occidentalis biotype from the Netherlands acquires TSWV only during the first larval instar (34), biotypes from other locations (e.g., Hawaiian islands, U.S. mainland, Israel) acquire TSWV during both larval instars $(30,34)$.

Corresponding author: D. Ullman; E-mail address: deullman@ucdavis.edu

Publication no. P-1997-1222-02R

(C) 1998 The American Phytopathological Society
Electron microscopy observations and several lines of circumstantial evidence implicate TSWV membrane GPs as viral attachment proteins. Immunolabeling of serial sections from larval midguts revealed that TSWV envelope GPs bound to the brush border plasmalemma (29). In the cytoplasm, adjacent to immunolabeled GPs on the brush border plasmalemma, amorphous masses of TSWV nucleocapsid (N) protein were observed. Deeper within these cells the TSWV encoded proteins were compartmentalized in inclusions, vacuoles, and vesicles (29). Endocytosis via coated vesicles was not observed, nor was virus seen enclosed in endosomes or uncoating within thrips cells. Based on these findings, we proposed that the viral GPs interact with a receptor in the plasma membrane of larval thrips' midgut epithelial cells, initiating virus fusion and release of replicative components into the cytoplasm. This mechanism of cell entry is consistent with that of other membrane-bound viruses, such as human immunodeficiency virus (HIV) $(10,27)$ and certain baculoviruses $(13)$.

In addition to evidence from our immunolocalization studies, circumstantial evidence supports the specific involvement of the TSWV GPs in virus acquisition by thrips. Repeated mechanical inoculation of TSWV to plants leads to envelope-deficient mutants with lost sequences encoding the GPs (8). Although these mutants infect host plants, they are no longer thrips-transmissible (37), suggesting the GPs are required for virus acquisition by the thrips. The occurrence of the arginine-glycine-aspartic acid (RGD) motif in GP2 (18), a characteristic of cell-adhesion molecules, supports the hypothesis that the GPs act as viral attachment proteins that interact with cellular receptors in thrips to mediate acquisition.

Gel overlay assays are routinely used with viruses infecting vertebrate cells to determine the interaction of putative viral attachment proteins with corresponding cellular receptors $(3,5-7,9,11$, $15,16,21)$. With plant viruses, the approach has been limited to investigating the relationship of the potato leafroll luteovirus (PLRV) with its aphid vector, Myzus persicae (33). Although a specific 
aphid protein involved in the acquisition of PLRV was not identified, a $63-\mathrm{kDa}$ protein produced by the aphid endosymbiont (Gro-EL or symbionin) was specifically attached to PLRV and facilitated virus transmission, perhaps by protecting PLRV in the aphid hemocoel (33).

In the studies described in this paper, we used gel overlay assays and immunolabeling to investigate the putative role of the TSWV GPs as viral attachment proteins and determine whether a corresponding cellular receptor may be present in thrips. A preliminary report has been published (2).

\section{MATERIALS AND METHODS}

Maintenance of TSWV. A TSWV isolate (formerly TSWVlettuce strain [TSWV-L]) collected from infected tomato on the Hawaiian island of Maui was used for production of antibodies and serological assays. The isolate was maintained by inoculation with $F$. occidentalis as previously described (28). Virus was isolated from Datura stramonium as previously described (24). Purified TSWV GPs were obtained from isolated TSWV virions after separation by sodium dodecyl sulfate-polyacrylamide gel electrophoresis (SDS-PAGE), using the techniques described by Adkins et al. (1).

Maintenance of insects. The $F$. occidentalis used in all experiments were maintained on pods of Phaseolus vulgaris as previously described (30). F. occidentalis were originally identified by D. Tsuda (Department of Entomology, University of Hawaii, Honolulu) and have been routinely subsampled for species identifications on a monthly basis. Larval and adult greenhouse thrips, Heliothrips haemorrhoidalis, were obtained from grape cuttings in greenhouses at the University of California, Davis, and identified by D. Ullman. We chose to use this thrips species because it is a direct pest of many plants that serve as TSWV hosts and despite this overlap is not known to transmit any of the tospoviruses. Leafhoppers (Circulifer tenellus) were obtained from J. Fletcher and A. Wayadande (Oklahoma State University, Stillwater) and identified by J. K. Bouseman (Illinois Natural History Survey, Champaign). Aphids (Schizaphis graminum) were obtained and identified by J. A. Webster (USDA-ARS, Stillwater, OK). We included these two insect species because they transmit a variety of plant viruses and phytoplasmas but are not vectors of any of the tospoviruses. Vouchers of all species are at the Bohart Museum of Entomology, University of California, Davis.

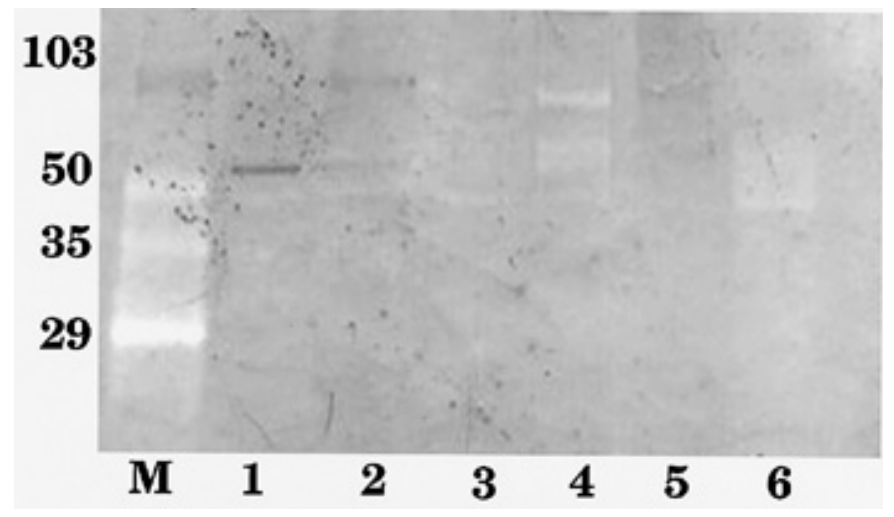

Fig. 1. Gel overlay assay of whole insects, with isolated tomato spotted wilt virus (TSWV) as the overlay. Blot was probed with monoclonal antibodies against TSWV glycoproteins (GPs). Lane 1, A 50-kDa protein in Frankliniella occidentalis larvae bound the TSWV GPs. Lane 2, A faint band was detected from preparations of western flower thrips adults. Binding was not detected in lanes containing separated proteins from nonvector insects: lanes 3 and 4, larvae and adults of Heliothrips haemorrhoidalis; lane 5, adult aphids, Schizaphis graminum; or lane 6, adult leafhoppers, Circulifer tenellus. Lane M, Molecular weights of standards from top to bottom are in kilodaltons.
Production of antibodies. The production and specificity of the murine monoclonal antibodies (MAbs) to either GP1 (1C5d3 $\left.3^{\mathrm{GPl}}\right)$ or GP2 $\left(8 \mathrm{C} 2 b^{\mathrm{GP} 2}\right)$ of TSWV has been previously described (1). Rabbit polyclonal antiserum to the nonstructural (NS) protein encoded by the small RNA of TSWV or to the TSWV N protein were produced as previously described $(30,31)$.

Ascites fluid containing anti-idiotype antibodies to murine MAbs $1 \mathrm{C} 5 \mathrm{~d} 3^{\mathrm{GP} 1}$ and $8 \mathrm{C} 2 \mathrm{~b}^{\mathrm{GP} 2}$ was produced in $\mathrm{C} 3 \mathrm{H} / \mathrm{HeN}$ mice using the following methods. MAbs $1 \mathrm{C} 5 \mathrm{~d} 3^{\mathrm{GP} 1}$ and $8 \mathrm{C} 2 \mathrm{~b}^{\mathrm{GP} 2}$ were isolated from culture supernatant by ammonium sulfate precipitation and resuspended in phosphate-buffered saline (PBS). A mouse received eight injections of $100 \mu \mathrm{g}$ each of murine MAb emulsified in Freund's incomplete adjuvant (Sigma Chemical Co., St. Louis) over a 18-week period. Ascites production was initiated by injecting sarcoma 180 cells (ATCC TIB-66). The ascitic fluid was harvested 16 days later, and the immunoglobulin fraction was obtained by ammonium sulfate batch precipitation.

Gel overlay assays. Overlay assays with TSWV or isolated viral proteins were conducted in a manner similar to that reported by van den Heuvel et al. (33). First and second instar larvae and adults of $F$. occidentalis, adult $S$. graminum and $C$. tenellus, or larvae and adults of $H$. haemorrhoidalis were macerated in $200 \mu \mathrm{l}$ of SDS-PAGE sample buffer (62 mM Tris-HCl, pH 6.8, $2 \%$ SDS, $10 \%$ glycerol, and 5\% 2-mercaptoethanol) and heated at $90^{\circ} \mathrm{C}$ for 5 min. Similar numbers of insects were used per well, and proteins were not purified or adjusted in any way to avoid inadvertently removing proteins of interest. For overlay assays with dissected $F$. occidentalis midguts, which are very small, extractions were stored in aliquots of $\approx 100 \mu \mathrm{g}$ of total protein. From these aliquots, samples containing $\approx 30 \mu \mathrm{g}$ of total protein from larvae and adults were prepared in SDS-PAGE sample buffer and subjected to SDS-PAGE, and separated thrips proteins were transferred to nitrocellulose.

The nitrocellulose was incubated in 5\% nonfat dry milk in Trisbuffered saline (TBS) for $60 \mathrm{~min}$ and rinsed three times in TBS. Isolated TSWV virions or gel-purified TSWV GPs were used as an overlay. Isolated TSWV was used at $10 \mu \mathrm{g}$ of total protein per $\mathrm{ml}$ in TBS, with $1 \%$ nonfat dry milk and isolated TSWV GPs at $10 \mu \mathrm{g} / \mathrm{ml}$. Blots were incubated with TSWV virions or TSWV

\section{3}

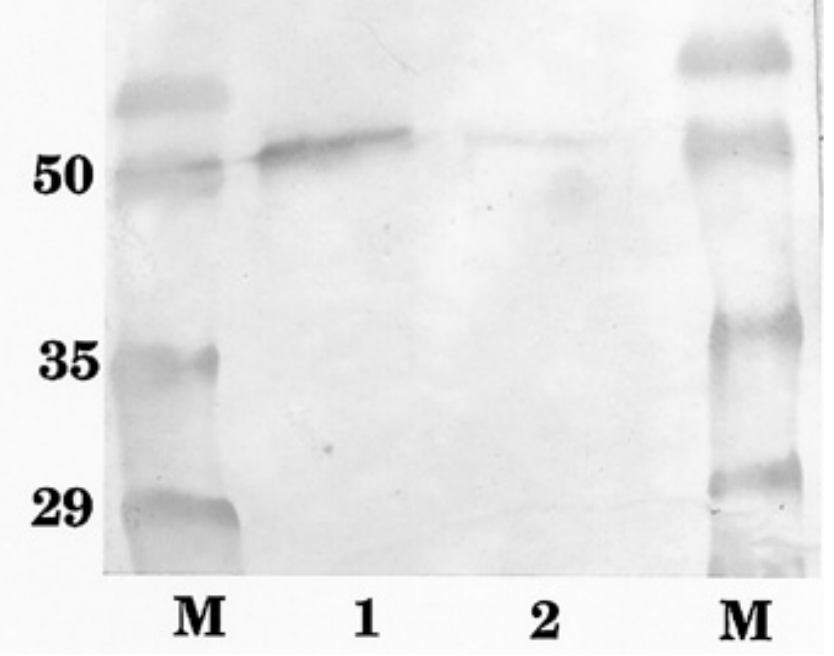

Fig. 2. Gel overlay assay of dissected midguts from Frankliniella occidentalis, with partially purified tomato spotted wilt virus (TSWV) as the overlay. Blot was probed with monoclonal antibodies against TSWV glycoproteins (GPs). Lane 1, Significant binding between a 50-kDa larval thrips protein and TSWV GPs was observed. Lane 2, A faint band at $50 \mathrm{kDa}$ also was observed from adults. Lane M, Molecular weights of standards from top to bottom are in kilodaltons. 
GPs for $3 \mathrm{~h}$ at room temperature. The blots were rinsed three times in TBS and incubated for $3 \mathrm{~h}$ at room temperature in antibody diluted in TBS with $1 \%$ nonfat dry milk. Antibodies to the GPs (murine MAbs $1 \mathrm{C} 5 \mathrm{~d} 3^{\mathrm{GP} 1}$ and $8 \mathrm{C}^{2} \mathrm{~b}^{\mathrm{GP} 2}$ ) or $\mathrm{N}$ or NS protein encoded by the small RNA were used at a 1:500 dilution based on the results of previous experiments $(1,30,31)$. Blots were rinsed three times in TBS, and antibody binding was detected by either goat anti-mouse or rabbit antibody conjugated to alkaline phosphatase (Sigma) followed by substrate. Control blots with no virus protein overlay in which separated insect proteins were transferred to nitrocellulose, blots were blocked and incubated in antibody (against the GPs or N or NS protein encoded by the small RNA) followed by the appropriate alkaline phosphatase conjugate, also were conducted. During our previous work on production of murine MAbs to the GPs, we found that isolation of GP1 and GP2 completely free of the other GP was not reliably possible, so the GPs were combined to probe these blots. Hence, the antibodies to the GPs also were combined. Assays with isolated TSWV virions as the overlay were replicated more than 10 times (Fig. 1), whereas assays with dissected midguts and isolated virions or GPs were replicated 4 times (Figs. 2 and 3). Larvae and adults of H. haemorrhoidalis were used as a nonvector controls in all assays, except those involving dissected midguts (Figs. 2 and 3).

Western blots measuring binding between thrips proteins and anti-idiotype antibodies against the murine MAbs to TSWV GPs were conducted with $F$. occidentalis and $H$. haemorrhoidalis (Fig. 4). Insect proteins were adjusted to $10 \mu \mathrm{g}$ of total protein per well, subjected to SDS-PAGE, and transferred to nitrocellulose. Blotted proteins were reacted with anti-idiotype antibodies $(5 \mu \mathrm{g} / \mathrm{ml})$, and

103

50

35

29

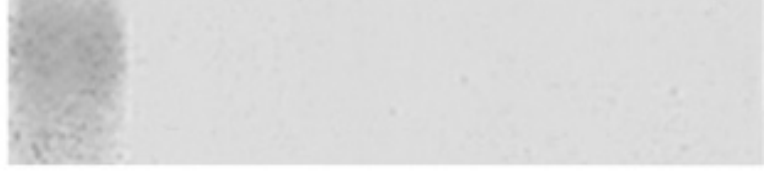

$\mathbf{M}$

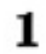

2

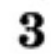

Fig. 3. Gel overlay assay of dissected midguts from Frankliniella occidentalis and extracts of whole Schizaphus graminum, with gel-isolated tomato spotted wilt virus (TSWV) glycoproteins (GPs)as the overlay. Blot was probed with monoclonal antibodies against TSWV GPs. Lane 3, Significant binding between a 50-kDa larval thrips protein and TSWV GPs was observed. Lane 2, A faint band at a slightly higher molecular weight also was observed from adults in one replication of this experiment. Lane 1, The GPs did not bind any proteins from aphid extracts. the binding of the anti-idiotype antibody was detected with avidin $\mathrm{DH}$ and biotinylated horseradish peroxidase $\mathrm{H}$ reagents following the manufacturer's directions (Vector Laboratories, Burlingame, CA). These experiments were replicated twice.

Immunolabeling of thrips midguts. Adult $F$. occidentalis were allowed to oviposit for 24 to $48 \mathrm{~h}$ in chambers consisting of a 7.62-cm-diameter tube closed at one end with silk screening (175 mesh) and covered at the other end with two layers of Parafilm enclosing 5\% sucrose solution. Thrips eggs were removed from between the Parafilm layers by vacuum filtration onto 47-mm 1.2- $\mu \mathrm{m}$ nylon membrane filters. The membrane filters were transferred to $60 \times 15-\mathrm{mm}$ petri dishes and stored in humid chambers until hatching. No plant material was present at any stage of this rearing cycle, thus midguts were free of plant products during immunolabeling. Larvae were collected and used for immunolabeling 0 to $12 \mathrm{~h}$ posteclosion. Midguts were dissected in insect physiological saline (IPS; $9.0 \mathrm{~g}$ of $\mathrm{NaCl}, 0.2 \mathrm{~g}$ of $\mathrm{NaHCO}_{3}, 0.2 \mathrm{~g}$ of $\mathrm{MgCl}_{2}, 0.2 \mathrm{~g}$ of $\mathrm{CaCl}_{2}, 0.2 \mathrm{~g}$ of $\mathrm{KCl}, 4.0 \mathrm{~g}$ of

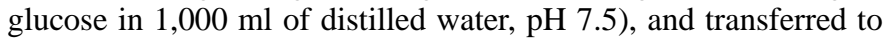
fresh IPS in a glass depression slide. All subsequent incubations and washes were performed within these wells. Although the thrips exoskeleton autoflouresced, we chose to keep the abdomens attached to the specimens because they enhanced our ability to transfer and locate tissues.

Saline was removed from the preparations as soon as possible, and $40 \mu \mathrm{l}$ of fixative $(0.2 \%$ glutaraldehyde, $4 \%$ paraformaldehyde in phosphate buffer, $\mathrm{pH} 7.4$ ) at room temperature was added for 1 min. Fixative was removed, and specimens were washed with $80 \%$ ethanol (twice for 5 min each) followed by washes with PBS (twice for $5 \mathrm{~min}$ each). PBS was removed, and the tissues were incubated in 5\% normal goat serum in PBS for $30 \mathrm{~min}$ at room temperature. The normal goat serum was removed, and the preparations were incubated overnight at room temperature in anti-idiotype antibodies to the murine MAbs, $1 \mathrm{C} 5 \mathrm{~d} 3^{\mathrm{GP} 1}$ or $8 \mathrm{C} 2 \mathrm{~b}^{\mathrm{GP} 2}$, diluted $1: 10$ or $1: 5$ in $1 \%$ normal goat serum in PBS. After incubation, preparations were washed five times for 2 min each with PBS and incubated for $1 \mathrm{~h}$ in fluorescein isothiocyanate (FITC; 1:500 in PBS). Preparations were washed with PBS (five times for $2 \mathrm{~min}$ each) and counterstained in Chicago blue-2 for 20 to $30 \mathrm{~min}$. After counterstaining, preparations were washed in PBS (five times for $2 \mathrm{~min}$ each), transferred to clean flat microscope slides, and mounted in 1:1 PBS/glycerol. Preparations were viewed and photographed on a Nikon Microphot SA microscope (Nikon Instrument Group, Melville, NY).

Twenty-two fully intact midguts were immunolabeled: eleven with the anti-idiotype antibody to murine $\mathrm{MAb} 1 \mathrm{C} 5 \mathrm{~d} 3^{\mathrm{GP} 1}$ and eleven with the anti-idiotype antibody to murine MAb $8 \mathrm{C} 2 b^{\mathrm{GP} 2}$. In one of these dissections, the salivary gland shown in Figure $5 \mathrm{C}$ and $\mathrm{D}$ was present. The remaining dissections did not include the salivary glands. Thirteen additional fully intact midguts were used as controls and treated as described, except they were incubated with $1 \%$ normal goat serum. Incubations were done in a humid chamber consisting of a sealed plastic container lined with paper towels dampened with $0.01 \%$ PBS, $\mathrm{pH}$ 7.2.

\section{RESULTS}

Gel overlay assays. Our results show that TSWV membrane GPs were selectively bound to thrips proteins from extracts of whole insects and dissected midguts. A single band in the region of $50 \mathrm{kDa}$ was detected in all gel overlay assays (Figs. 1 through 3). Assays with separated proteins from whole thrips and isolated virus as the overlay revealed a single band at $50 \mathrm{kDa}$ from $F$. occidentalis larvae and adults when probed by MAbs to GP1 and GP2 (Fig. 5). Results similar to those shown in Figure 5 were obtained when polyclonal antibodies to the GPs were used as probes (data not shown). In all the replications of this assay (more than 10), a difference in the intensity of the bands from larvae and adults was observed, with only a faint band detected from adults 
(Fig. 5). Bands at or near $50 \mathrm{kDa}$ were absent in lanes containing preparations of all the nonvector insect species tested (S. graminum, C. tenellus, and $H$. haemorrhoidalis). Furthermore, no bands were detected from separated proteins of any of the insects assayed when polyclonal antibodies against TSWV N protein or the NS protein encoded by the small RNA were used as probes, nor did any of the antibodies react with separated insect proteins in the absence of virus protein overlays (data not shown).

Similar results were obtained in assays with blots of separated proteins from dissected thrips midguts and isolated virus or gelpurified TSWV GPs as the overlay (Figs. 2 and 3, respectively). A single band at or near $50 \mathrm{kDa}$ was detected from separated larval and adult $F$. occidentalis proteins. Although similar quantities of thrips midgut protein were loaded per lane from larval and adult samples, the band detected from larval midgut preparations was very intense, whereas only a faint band could be observed from adult preparations. As in experiments with isolated TSWV as the overlay, no bands were observed from aphid extracts, indicating that gel-purified TSWV GPs did not bind aphid proteins (Fig. 3). In one of the four replications of these assays, the band resulting from adult thrips extracts was present at a slightly higher molecular weight (Fig. 3).

Western blot and immunolabeling assays with anti-idiotype antibodies to murine MAbs against TSWV GP1 or GP2. The anti-idiotype antibodies against the murine MAbs to GP1 and GP2 provide reagents that mimic TSWV GPs and can be detected by a tagged anti-mouse antibody. In Western blots with insect proteins, both anti-idiotype antibodies labeled a single band at $50 \mathrm{kDa}$ in wells containing extracts of $F$. occidentalis but did not label bands at this molecular weight from $H$. haemorrhoidalis (Fig. 4). As observed in gel overlay assays, the band in lanes containing larval preparations was intense, whereas the band in lanes containing adult preparations was faint, although the same amount of thrips protein was loaded on each lane.

Immunolabeling experiments revealed that the anti-idiotype antibodies bound specifically to the plasmalemma of the epithelial cells of dissected larval midguts, an expected location for cellular receptors (Fig. 5). Phase-contrast views of each midgut preparation are shown in Figure 5A, C, and E for orientation purposes. The specificity of the labeling reactions is supported by the control, in which no labeling was detected when midgut tissues were reacted with normal goat serum and FITC-conjugated antibody (Fig. 5B). Although the insect exoskeleton autoflouresced, this did not detract from our ability to differentiate labeling in dissected soft tissues. The GP1 anti-idiotype consistently resulted in specific fluorescence of internal epithelial plasmalemma, giving the cells an outlined appearance (Fig. 5D). Labeling with the GP2 anti-idiotype resulted in specific fluorescence of the basal membranes of the midgut with only a slight reaction with internal membranes (Fig. 5F). Only one dissection contained the salivary glands; however, it is interesting that fluorescence of the basal membrane of one gland was observed (Fig. 5D).

\section{DISCUSSION}

Our results, in combination with previous electron microscopy findings $(31,32)$, support the hypothesis that the TSWV GPs serve as viral attachment proteins that interact with one or more cellular receptors in the thrips midgut. This conclusion is supported by several pieces of evidence. First, TSWV GPs selectively bind separated $F$. occidentalis proteins that form a single band at or near $50 \mathrm{kDa}$ but do not bind separated proteins from nonvector insects, including another species in the family Thripidae (Figs. 1 through 3). The consistent difference in band intensity in lanes containing larval versus adult extracts indicates that the abundance of putative cellular receptor(s) is greater in larvae, the developmental stage known to acquire the virus, than in adults, which are refractory to the virus. The latter finding is consistent with previous hypotheses that receptor abundance is an important determinant of vector competence with membrane-bound viruses $(12,14)$, as well as governing endocytosis of Bacillus thuringiensis delta-endotoxins (35). Proteins that serve as virus receptors generally serve some other fundamental function in the host (22). Therefore, finding a potential cellular receptor for TSWV that is present in larvae and adults of $F$. occidentalis is quite plausible, even though the adult does not acquire the virus. Given the importance of $\mathrm{pH}$ and proteases in mediating endocytosis of membrane-bound viruses $(4,20,36)$, we also expect that the physiology of the thrips midgut will be important in determining whether interactions between viral proteins and cellular receptors lead to virus acquisition. By analogy to other membrane-bound viruses, it is likely that TSWV endocytosis would be mediated by receptor abundance in combination with other factors that might vary between larvae and adults, i.e., processing of viral proteins governed by conditions in the midgut or formation of transient structures, such as a peritrophic membrane. This hypothesis is consistent with biological

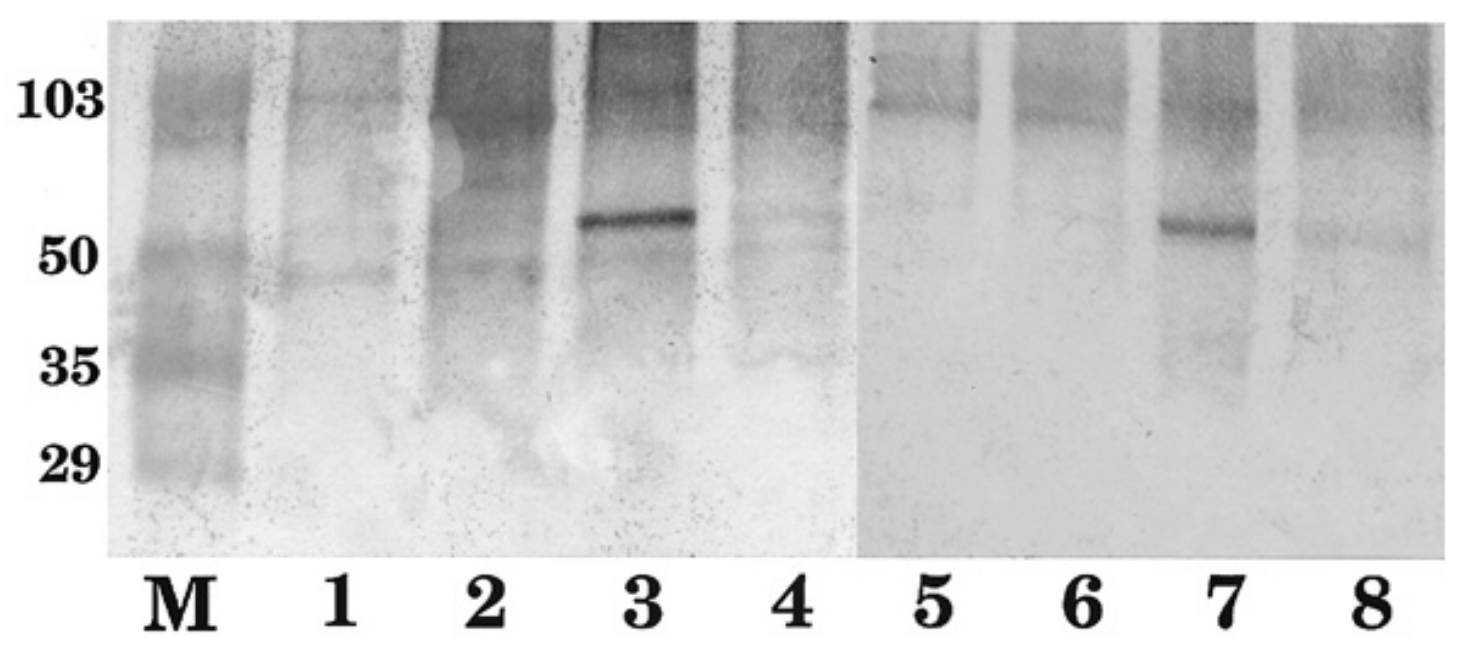

Fig. 4. Results of Western blots on which anti-idiotype antibodies to the murine monoclonal antibodies against tomato spotted wilt virus (TSWV) glycoproteins lanes 1 through 4, GP1 or lanes 5 through 8, GP2 were used to probe separated proteins from larvae and adults of $H$. haemorrhoidalis and $F$. occidentalis. Lanes 1 and 5, H. haemorrhoidalis larvae. Lanes 2 and 6, H. haemorrhoidalis adults. Lanes 3 and 7, F. occidentalis larvae. Lanes 4 and 8, F. occidentalis adults. A single band was detected at $50 \mathrm{kDa}$ in wells containing $F$. occidentalis preparations. The band in lanes containing larvae was intense, whereas the band in lanes containing adults was faint, although the same amount of thrips protein was loaded on each lane. No bands were detected at or near $50 \mathrm{kDa}$ in lanes containing larvae or adults of $H$. haemorrhoidalis. 

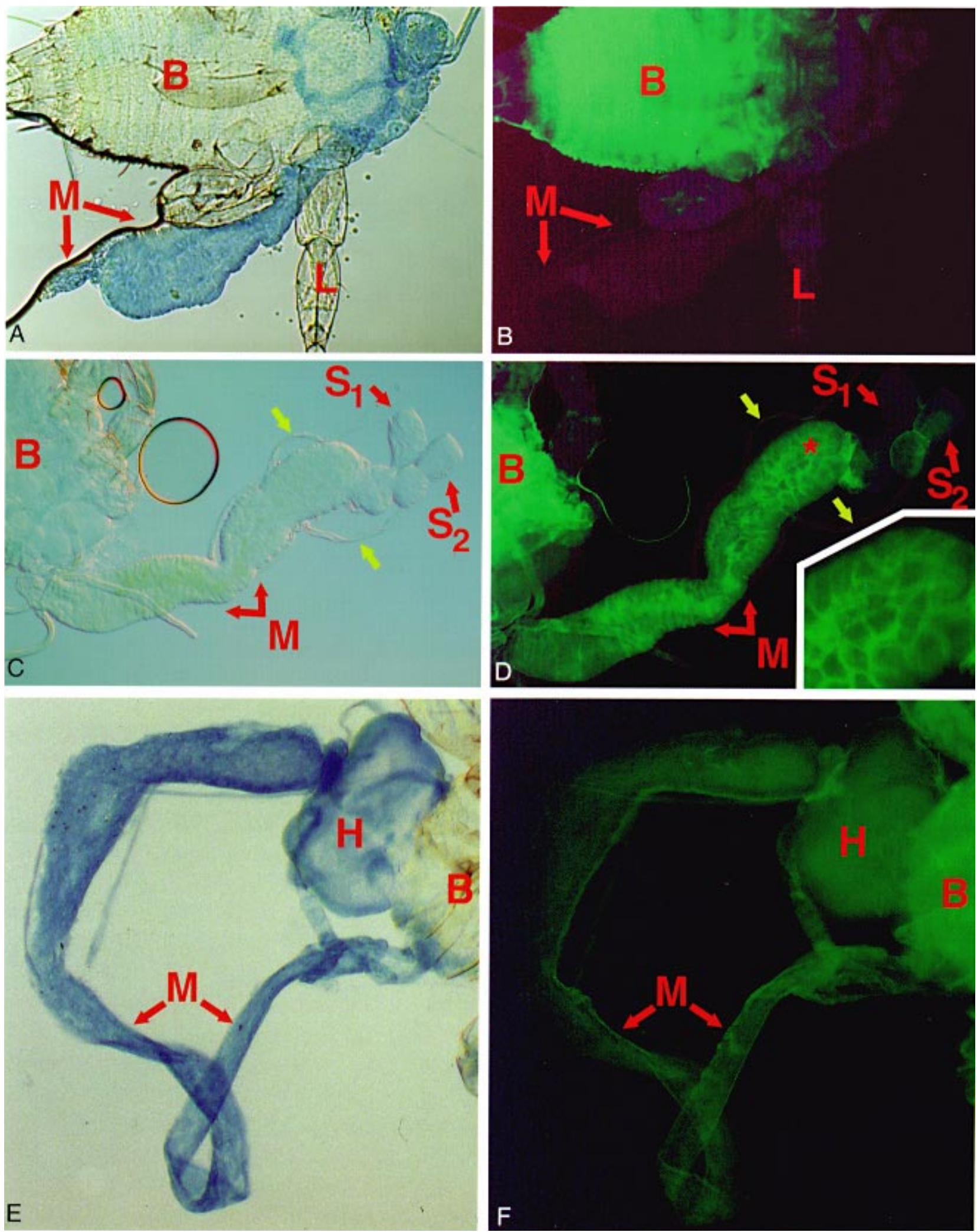

Fig. 5. Labeling of first instar western flower thrips midgut membranes with anti-idiotype antibodies to tomato spotted wilt virus memb rane glycoproteins (GP1 and GP2). Dissected thrips midguts were reacted with the anti-idiotypic antibodies and compared to control dissections reacted with normal serum. A, C, and $\mathbf{E}$, Dissections under transmitted light. B, D, and F, Fluorescein isothiocyanate fluorescence of the same dissections seen in $\mathbf{A}, \mathbf{C}$, and $\mathbf{E}$, respectively, under B2 (blue, $495 \mathrm{~nm}$ ) light. A, Control, dissection reacted with normal serum. B, Same dissection as in A. Auto fluorescence of the body and legs is evident, but midgut cells do not fluoresce. Arrows indicate the location of the midgut. C, Dissection reacted with the anti-idiotype to GP1. Contours of midgut epithelial cells are evident. D, Same dissection shown in C. Plasma membranes (plasmalemma) bounding the midgut epithelial cells fluoresce specifically. As in the controls (B), the body and legs auto fluoresce. No labeling of the basement membrane was observed. The salivary gland was present in only one dissection, but the basal membranes of one gland $\left(\mathrm{S}_{2}\right)$ and the tubular salivary glands (unmarked yellow arrows) did fluoresce. D, Inset: Higher magnification of midgut region under the asterisk. Labeling of the plasmalemma can be clearly seen. E, Dissection reacted with the anti-idiotype to GP2. F, Same dissection as in E. Basal membranes of the midgut fluoresce specifically. $\mathrm{B}=$ body; $\mathrm{H}=$ hindgut; $\mathrm{M}=$ midgut; $\mathrm{S}_{1}$ and $\mathrm{S}_{2}=$ two lobes of the primary salivary gland; unmarked arrows $=$ tubular salivary glands. 
data showing that the efficiency of virus acquisition by larvae is reduced dramatically as development proceeds, with the highest level of acquisition occurring during the first few hours of the first instar larvae (34).

The specificity of binding between the TSWV GPs and separated thrips proteins in our assays is supported by the finding that neither the N nor the NS viral protein tested was detected binding to this protein in F. occidentalis. No labeling occurred when anti$\mathrm{GP}$, anti-N protein, or anti-NS protein antibodies were reacted directly with separated $F$. occidentalis proteins in the absence of viral protein in the overlay procedure. The significance of the slight difference in the molecular weight of bands from larval and adult extracts in one gel overlay assay with isolated GPs as the overlay (Fig. 3) is unknown. Based on criteria routinely used to tentatively identify proteins as possible receptors for virus acquisition (36), i.e., similarity in molecular weight and serological activity, our data support the hypothesis that a 50-kDa thrips protein serves as a cellular receptor or component thereof for TSWV acquisition. The results of Western blotting, in which anti-idiotype antibodies against the murine MAbs to the TSWV GPs bound to a single 50-kDa F. occidentalis protein (Fig. 4), also suggest the involvement of a single protein. Because the anti-idiotypes mimic the TSWV GPs, these data also provide especially important evidence that binding events we observed are specific and that the $50-\mathrm{kDa}$ thrips protein we observed is a cellular receptor or component thereof.

Finally, the midgut plasmalemma, the expected location of a cellular receptor in thrips, was specifically labeled when thrips midguts were reacted with the anti-idiotype antibodies (Fig. 5). The specificity of the labeling in these experiments is well supported by the lack of fluorescence from the midguts of control insects (Fig. 5B). Comparison of the midgut tissues in Figure 5B with those shown in Figure 5D and F show that autofluorescence of the chitinous exoskeleton did not detract from our ability to detect specific fluorescence in the soft tissues dissected from the thrips. The significance of differential labeling of the thrips midgut plasmalemma with the anti-idiotype antibodies (Fig. 5D and F) is not yet understood. One possible explanation is that these antibodies, which mimic the TSWV GPs, detected a component of two different cellular receptors that interact with the viral GPs under different circumstances. Support for this hypothesis is found in a similar interaction thought to occur with another member of the family Bunyaviridae, LACV (20). In the LACV-mosquito vector interaction, the evidence indicates that mosquito cell lines possess separate receptors for GP1 and GP2. Furthermore, the conditions of the mosquito vector midgut remove GP1 from the virus, exposing GP2 to serve as a viral attachment protein mediating entry to the insect midgut. When the virus replicates in the midgut and mature particles are produced, GP1 is thought to cover GP2 and serve as the viral attachment protein, mediating virus translocation to other organs in the insect and binding to vertebrate cells.

Our findings strongly support the role of TSWV GPs as viral attachment proteins and the presence of one or more putative cellular receptors in the thrips midgut. This conclusion is consistent with the most commonly accepted models of virus entry for membrane-bound viruses, including other members of the family Bunyaviridae (i.e., LACV [20]), HIV [10,27], and certain baculoviruses [13]). These investigations and many others (reviewed in $[26,36])$ indicate that viral GPs serve as attachment proteins, and virus fusion to host cells results from a conformational change in the GPs that is driven by receptor binding or acidic $\mathrm{pH}$ (4). The tospoviruses infect their vectors in much the same way as insectpathogenic viruses or mosquito-transmitted animal viruses. Although no cellular receptors have been identified for insect vectors of plant viruses or vectors of animal-infecting bunyaviruses, several receptors have been characterized for insect-pathogenic viruses and other mosquito-transmitted animal viruses, i.e., polyhedron-derived baculovirus (13), the B. thuringiensis crylA(b) and
crylA(c) delta-endotoxins $(17,32)$ and WEEV (14). These studies localized cellular receptors to the brush border membrane of the host cells and provide additional support for our contention that a putative cellular receptor is localized at the midgut plasmalemma of thrips. Experiments are underway to further support this proposal by demonstrating saturable attachment of virus to host cells, virus competition for limited receptor sites, and characterization of the binding motif in the GPs.

\section{LITERATURE CITED}

1. Adkins, S., Choi, T.-J., Israel, B. A., Bandla, M. D., Richmond, K. E., Schultz, K. T., Sherwood, J. L., and German, T. L. 1996. Baculovirus expression and processing of the tomato spotted wilt virus glycoproteins. Phytopathology 86:849-855.

2. Bandla, M. D., Westcot, D. M., Ullman, D. E., and Sherwood, J. L. 1995. Thrips midgut proteins that bind to tomato spotted wilt tospovirus glycoproteins. Pages 341-349 in: Proc. Int. Symp. Tospoviruses Thrips Floral Veg. Crops. Acta Hortic., vol. 431. G. G. Kuo, D. Peters, and T. L. German, eds. International Society for Horticultural Science, Wageningen, Netherlands.

3. Boyle, J. F., Weismiller, D. G., and Holmes, K. V. 1987. Genetic resistance to mouse hepatitis virus correlates with absence of virus-binding activity on target tissue. J. Virol. 61:185-189.

4. Carrasco, L. 1994. Entry of animal viruses and macromolecules into cells. FEBS Lett. 350:151-154.

5. Compton, S. R., Stephensen, C. B., Snyder, S. W., Weismiller, D. G., and Holmes, K. V. 1992. Coronavirus species specificity: Murine coronavirus binds to a mouse-specific epitope on it carcinoembryonic antigen related receptor glycoprotein. J. Virol. 66:7420-7428.

6. Crane, S. E., Buzy, J., and Clements, J. E. 1991. Identification of cell membrane proteins that bind visna virus. J. Virol. 65:6137-6143.

7. Dalziel, R. G., Hopkins, J., Watt, N. J., Dutia, B. M., Clarke, H. A. K., and McConnell, I. 1991. Identification of a putative cellular receptor for the lentivirus visna virus. J. Gen. Virol. 72:1905-1911.

8. de Resende, O. R., de Haan, P., de Avila, A. C., Kitajima, E. W., Kormelink, R., Goldbach, R., and Peters, D. 1991. Generation of envelope and defective interfering RNA mutants of tomato spotted wilt virus by mechanical passage. J. Gen. Virol. 72:2375-2383.

9. Dveksler, G. S., Dieffenbach, C. W., Cardellichio, C. B., McCuaig, K., Pensiero, M. N., Jiang, G.-S., Beauchemin, N., and Holmes, K. V. 1993. Several members of the mouse carcinoembryonic antigen-related glycoprotein family are functional receptors for the coronavirus mouse hepatitis virus-A59. J. Virol. 67:1-8.

10. Freed, E. O., and Risser, R. 1990. The role of the HIV envelope glycoproteins in cell fusion and the pathogenesis of AIDS. Bull. Inst. Pasteur 88:73-110.

11. Gershoni, J. M., Lapidot, M., Zakai, N., and Loyter, A. 1986. Protein blot analysis of virus receptors: Identification and characterization of the Sendai virus receptor. Biochim. Biophys. Acta 856:19-26.

12. Hardy, J. L., Houk, E. J., Kramer, L. D., and Reeves, W. C. 1983. Intrinsic factors affecting vector competence of mosquitoes for arboviruses. Annu. Rev. Entomol. 28:229-262.

13. Horton, H. M., and Burand, J. P. 1993. Saturable attachment sites for polyhedron-derived baculovirus on insect cells and evidence for entry via direct membrane fusion. J. Virol. 67:1860-1868.

14. Houk, E. J., Arcus, Y. M., Hardy, J. L., and Kramer, L. D. 1990. Binding of western equine encephalomyelitis virus to brush border membrane fragments isolated from mesenteronal epithelial cell of mosquitoes. Virus Res. 17:105-118.

15. Jin, Y.-M., Pardoe, I. U., Burness, A. T. H., and Michalak, T. I. 1994. Identification and characterization of the cell surface 70-kilodalton sialoglycoprotein(s) as a candidate receptor for encephalomyocarditis virus on human nucleated cells. J. Virol. 68:7308-7319.

16. Karger, A., and Mettenleiter, T. C. 1996. Identification of cell surface molecules that interact with pseudorabies virus. J. Virol. 70:2138-2145.

17. Knight, P. J. K., Knowles, B. H., and Ellar, D. J. 1995. Molecular cloning of an aminopeptidase $\mathrm{N}$ that serves as a receptor for Bacillus thuringiensis CryIA(c) toxin. J. Biol. Chem. 270:17765-17770.

18. Kormelink, R., de Haan, P., Meurs, C., Peters, D., and Goldbach, R. 1992. The nucleotide sequence of the M RNA segment of tomato spotted wilt virus, a bunyavirus with two ambisense RNA segments. J. Gen. Virol. 73:2795-2804.

19. Ludwig, G. V., Christensen, B. M., Yuill, T. M., and Schultz, K. T. 1989. Enzyme processing of La Crosse virus glycoprotein G1:a bunyavirusvector infection model. Virology 171:108-113.

20. Ludwig, G. V., Israel, B. A., Christensen, B. M., Yull, T. M., and Schultz, K. T. 1991. Role of La Crosse virus glycoproteins in attachment of virus 
to host cells. Virology 181:564-571.

21. Mizukami, H., Young, N. S., and Brown, K. E. 1996. Adeno-associated virus type 2 binds to a 150-kilodalton cell membrane glycoprotein. Virology 217:124-130.

22. Rossmann, M. G. 1994. Viral cell recognition and entry. Protein Sci. 3: 1712-1725.

23. Sakimura, K. 1962. The present status of thrips-borne viruses. Pages 3340 in: Biological Transmission of Disease Agents. K. Maramorosch, ed. Academic Press, New York.

24. Sherwood, J. S., Sanborn, M. R., Keyser, G. C., and Myers, L. D. 1989. Use of monoclonal antibodies in detection of tomato spotted wilt virus. Phytopathology 79:61-64.

25. Shope, R. E. 1985. Bunyaviruses. Pages 1055-1082 in: Virology. B. N. Fields, ed. Raven Press, New York.

26. Steggmann, T., Doms, R. W., and Helnius, A. 1989. Protein mediated membrane fusion. Annu. Rev. Biophys. Chem. 18:187-211.

27. Stein, B. S. D. G. S., Lifson, J. D., Penhallow, R. C., Bensch, K. G., and Engleman, E. G. 1987. pH independent HIV entry into CD4-positive T cells via virus envelope fusion to the plasma membrane. Cell 49:659-668.

28. Ullman, D. E., Cho, J. J., Mau, R. F. L., Westcot, D. M., and Custer, D. M. 1992. Midgut epithelial cells act as a barrier to tomato spotted wilt virus acquisition by adult western flower thrips. Phytopathology 82:1333-1342.

29. Ullman, D. E., German, T. L., Sherwood, J. S., and Westcot, D. M., 1995. Thrips transmission of Tospoviruses: Future possibilities for management. Pages 135-152 in: Thrips Biology and Management. B. L. Parker, M. Skinner, and T. S. Lewis, eds. Plenum Press, New York.
30. Ullman, D. E., German, T. L., Sherwood, J. L., Westcot, D. M., and Cantone, F. A. 1993. Tospovirus replication in insect vector cells: Immunocytochemical evidence that the nonstructural protein encoded by the S RNA of tomato spotted wilt tospovirus is present in thrips vector cells. Phytopathology 83:456-463.

31. Ullman, D. E., Westcot, D. M., Chenault, K. D., Sherwood, J. L., German, T. L., Bandla, M. D., Cantone, F. A., and Duer, H. L. 1995. Compartmentalization, intracellular transport, and autophagy of tomato spotted wilt tospovirus proteins in infected thrips cells. Phytopathology 85:644-654.

32. Vadlamudi, R. K. 1995. Cloning and expression of a receptor for an insecticidal toxin of Bacillus thuringiensis. J. Biol. Chem. 270:5490-5494.

33. van den Heuvel, J. F. J. M., Verbeek, M., and van der Wilk, F. 1994 Endosymbiotic bacteria associated with circulative transmission of potato leafroll virus by Myzus persicae. J. Gen. Virol. 75:2559-2565.

34. van de Wetering, F., Goldbach, R., and Peters, D. 1996. Tomato spotted wilt tospovirus ingestion by first instar larvae of Frankliniella occidentalis is a prerequisite for transmission. Phytopathology 86:900-905.

35. van Rie, J., Jansens, S., Hofte, H., Degheele, D., and van Mellaert, H. 1989. Specificity of Bacillus thuringiensis delta-endotoxins. Eur. J. Biochem. 186:239-247.

36. White, J. M. 1990. Viral and cellular membrane fusion proteins. Annu. Rev. Physiol. 52:675-697.

37. Wijkamp, I. 1995. Virus-vector relationships in the transmission of tospoviruses. Ph.D. dissertation. Agricultural University Wageningen, Wageningen, Netherlands. 